Contemporary Herpetology

ISSN 1094-2246

2000 Number 1

9 March 2000

\title{
VARIATION IN BODY TEMPERATURE AND THERMOREGULATORY BEHAVIOR BETWEEN TWO POPULATIONS OF THE LESSER EARLESS LIZARD, HOLBROOKIA MACULATA
}

Stephen B. Hager ${ }^{1}$ (bihager@augustana.edu)

Department of Biology, New Mexico State University, Las Cruces, New Mexico

${ }^{1}$ Current address: Department of Biology, Augustana College, Rock Island, Illinois 61201-2296

Abstract. Body temperatures and thermoregulatory behavior of fieldactive Holbrookia maculata were evaluated for two sites at approximately equal elevation (approximately1200 m) in southern New Mexico: 1) a population at White Sands National Monument, and 2) a population at the Jornada Long-term Ecological Research site. H. maculata at WS had significantly lower body temperatures (mean = $36.3^{\circ} \mathrm{C}$ ) than those measured at the Jornada Long-term Ecological Research site (mean $=39.5^{\circ} \mathrm{C}$ ). The slope of a regression of body temperature on air temperature was significantly different between populations (White Sands National Monument; 0.65 , the Jornada Long-term Ecological Research site; 0.36). The microhabitats in which individuals were first observed correlated with body temperatures at White Sands National Monument, but not at the Jornada Long-term Ecological Research site. These data suggest that environmental temperature differences between sites influenced body temperatures and thermoregulation in behavior $H$. maculata.

\section{INTRODUCTION}

Since the seminal work of Cowles and Bogert (1944) a large body of reptilian research has been devoted toward understanding how lizards interact with their thermal environments. The contention that all species maintain a narrow range of body temperatures through physiological (Heath 1964) and behavioral (Cowles and Bogert 1944) adjustments has been modified by research showing that this range can be broad when species are examined across seasons and populations (Huey et al. 1977; Grant and Dunham 1990; Smith and Ballinger 1994; Van Damme et al. 1989, 1990). For example, Bashey and Dunham (1997) have recently shown that microhabitat use and activity patterns differed between high elevation and low elevation populations of Cophosaurus texanus. These studies suggest that the thermal environment has the potential to influence the behavior and physiology of lizards. 
The lesser earless lizard, Holbrookia maculata, is a medium-sized, semi-arenicolous phrynosomatid found across much of the Great Plains of the United States, including southern New Mexico (Degenhardt et al. 1996). It is associated with sandy blowouts (disturbed sites with sparse vegetation; Ballinger and Jones 1985). Within the range of this species is a population that inhabits gypsum $\left(\mathrm{CaSO}_{4}-\mathrm{nH}_{2} \mathrm{O}\right)$ sand dunes at White Sands National Monument (WS), New Mexico (Ruthven 1907). The thermal environment at WS is generally "cooler" than non-gypsum environs outside of the dunes (Dixon 1967). This difference arises because of the physical properties of gypsum (V. Gutschick, pers. comm.), which include high reflectivity (Wheeler et al. 1994), low thermal capacity for heat exchange (Weast 1986), and evaporation from shallow subterranean water (Houk and Collier 1994). Sufficiently low environmental temperatures could influence body temperatures of this lizard and, therefore, its ability to thermoregulate, forage, grow, mate, and escape predation.

Few studies have examined thermoregulation in Holbrookia maculata. Sena (1978) reported a mean body temperature of $34.3^{\circ} \mathrm{C}(\mathrm{N}=174)$ for a population in eastern New Mexico. Brattstrom (1965) collected body temperatures from three individuals (locations not reported) and calculated a mean body temperature of 37.8 ${ }^{\circ} \mathrm{C}$. Individuals housed within semi-natural enclosures had a mean preferred body temperature of $35.7^{\circ} \mathrm{C}(\mathrm{N}=41)$ (Clarke 1965). Dixon (1967) recorded body temperatures of $H$. maculata at WS that ranged from $35^{\circ} \mathrm{C}$ to $39^{\circ} \mathrm{C}$ (no mean was published). He observed that they became inactive when soil temperatures reached 40 ${ }^{\circ} \mathrm{C}$ during hot summer afternoons. Hager (1998) found that WS lizards were active above the soil surface at soil temperatures ranging between $12.2^{\circ}$ and $45.8^{\circ} \mathrm{C}$ and documented a unimodal pattern of activity from June to August. These data demonstrate that body temperatures and some thermal relationships vary across the range of $H$. maculata.

My goal was to determine the influence of the thermal environment on $\mathrm{H}$. maculata. I measured environmental temperatures and body temperatures, and evalutated microhabitat use of lizards in thermally divergent habitats at WS and adjacent nongypsiferous areas in New Mexico.

\section{METHODS}

All data were collected from two sites at similar elevations (approximately $1200 \mathrm{~m}$ ) in southern New Mexico: 1) White Sands National Monument (WS) $\left(32^{\circ} 47^{\prime} \mathrm{N}\right.$; $\left.106^{\circ} 11^{\prime} \mathrm{W}\right)$, and 2$)$ Jornada Long-term Ecological Research site $(\mathrm{JRN})\left(32^{\circ} 37^{\prime} \mathrm{N} ; 106^{\circ} 44^{\prime} \mathrm{W}\right)$. The sites are separated by $60 \mathrm{~km}$ and by the San Andres mountain range. I conducted fieldwork approximately two days weekly during April-August of 1995 to 1997. Consistent afternoon and evening thunderstorms restricted work to mostly the morning and early 
afternoon hours (i.e., from 0700 to $1300 \mathrm{~h} \mathrm{MDT).} \mathrm{At} \mathrm{WS,} \mathrm{all} \mathrm{work} \mathrm{was}$ conducted in the active dunes where the substratum is composed almost exclusively of white gypsum (hydrous calcium sulfate). Plant cover in this area is sparse, although interdune depressions are dotted with various grasses (Oryzopsis sp., Sporobolus sp.), sand verbena (Phyla incisa), primrose (Anogra gypsophila), mormon tea (Ephedra torrreyana), yucca (Yucca elata), and rabbitbush (Chrysothamnus nauseosus). At JRN, all work was conducted in disturbed (by cattle grazing) grassland habitats composed of grasses (Bouteloua sp.), yucca (Yucca elata), mormon tea (Ephedra torrreyana), and various cacti (Opuntia spp.).

Body temperatures $\left(T_{b}\right)$ were taken from active lizards that were chased less than 10 $\mathrm{m}$. I assumed that all individuals were sampled once because only previously unsampled areas were visited during each survey. Lizards were noosed and Tb's taken within $10 \mathrm{sec}$ from individuals handled only by the rear limbs. Measurements to the nearest $0.2^{\circ} \mathrm{C}$ were made using a quick reading cloacal thermometer. Air temperatures ( $T_{a}$ ) were measured at $1 \mathrm{~cm}$ above the soil surface with shaded bulb. Soil temperatures $\left(T_{s}\right)$ were recorded from just below the soil surface, with only approximately one layer of soil particles covering the top of the bulb. Each of these was taken at the location where a lizard was first observed.

I also recorded snout-vent length (SVL), snout-tail length (STL), and body mass (BM) for each lizard. I calculated body condition (a representation of surface area/volume) for each population according to $\mathrm{BM}^{1 / 3} / \mathrm{SVL}$. Lengths were measured (nearest millimeter with a ruler) and body mass (BM; nearest 0.2 grams) was recorded from a 10 gram Pesola spring scale.

I used six categories to note the microhabitat where each lizard was first sighted: open (in full sun), open-hummock (in full sun on a hummock topped with short forbs or perennials), edge (<50\% estimated shade), under ( $>50 \%$ estimated shade), perched (on top of low-lying forb), and arboreal (within canopy of shrub).

All statistical tests were performed on JMP software for Macintosh (SAS Institute 1995) with alpha $=0.05$. For each variable the Shapiro-Wilk test (Zar 1984) was used to evaluate normality. Where the assumptions of parametric tests were violated, nonparametric tests were used. I evaluated differences in SVL and BM between populations with Kruskal-Wallis tests. Analysis of variance was used to analyze intrapopulational differences in $T_{a}, T_{s}, T_{b}$, and body condition. For each population, I used analysis of variance to test 1) the correlation between $T_{b}$ and $T_{a} ; 2$ ) the correlation of SVL and BM with $\mathrm{T}_{b} ; 3$ ) the correlation of month on $\mathrm{T}_{b}, \mathrm{~T}_{\mathrm{a}}$, and $\mathrm{T}_{\mathrm{s}} ; 4$ ) the correlation between microhabitat and $\mathrm{T}_{\mathrm{b}}$; and 5) correlation between time of day, $\mathrm{T}_{\mathrm{a}}$ and $\mathrm{T}_{\mathrm{s}}$ and microhabitat. I employed a t-test to compare the slopes of the regression of $T_{b}$ on $T_{a}$ in each population. 


\section{RESULTS}

Holbrookia maculata at WS had significantly lower Tb's than those at JRN (Table 1). Air temperatures were also significantly lower at WS than at JRN, as were Ts's (Table 1). Body temperature was positively correlated with $T_{a}$ at both WS and JRN, although $\mathrm{T}_{\mathrm{b}}$ followed $\mathrm{T}_{\mathrm{a}}$ more closely at WS than at JRN (WS: $\mathrm{df}=188, \mathrm{r}^{2}=0.59, \mathrm{P}<0.0001$; JRN: $\left.d f=68, r^{2}=0.48, P<0.0001\right)$; the slopes of the regressions differed significantly (t $=6.36, \mathrm{P}=0.001$ ) (Figure 1).

Body temperatures of lizards at WS and JRN were not related with SVL (WS: $P=0.84$, JRN: $P=0.71$ ) or $B M(W S: P=0.10, J R N ; P=0.91)$. At WS, $T_{b}(P=0.13), T_{a}(P=$ $0.45)$, and $T_{s}(P=0.98)$ did not vary among months. Conversely, $T_{b}\left(F_{3,85}=4.79, P=\right.$ $0.004), T_{a}\left(F_{3,67}=6.70, P=0.0005\right)$ and $T_{s}\left(F_{3,72}=4.71, P=0.0005\right)$ were influenced by month at JRN.

Microhabitat was correlated with $\mathrm{T}_{\mathrm{b}}$ at WS $\left(\mathrm{F}_{5,161}=6.70, \mathrm{P}<0.0001\right)$, but not at JRN $(\mathrm{P}$ $>0.33$ ) (Figure 2). Microhabitat selection varied with time of day in both populations (WS: $F_{5,130}=42.4, P=0.003 ; J R N: F_{5,51}=37.9, P=0.009$ ) (Figure 3). In the early morning hours WS lizards basked in direct sunlight in the open hummock and open microhabitats (Figure 3A). In each of these, lizards were positioned with the dorsum facing the sun and the venter applied to the ground. As Tb's increased lizards were found in the open (still in direct sunlight) but with their heads facing the sun and their venters held above the ground. Above Tb's of $36.6^{\circ} \mathrm{C}$, lizards shuttled between partial (edge) or full shade and the open. The highest mean Tb's were taken from perched individuals. White Sands lizards were never observed in the arboreal microhabitat, even though this microhabitat was present. Holbrookia maculata at JRN showed no relationship between Tb's and microhabitat (Figure 2). Generally, lizards basked in the open and perched on vegetation in the early morning (Figure 3B). The edge and arboreal microhabitats were used increasingly during late and early afternoon hours. Individuals used Ephedra exclusively for arboreal perches. The open/hummock microhabitat was not present at JRN. Air temperatures were related to microhabitat at both WS $\left(F_{4,114}=6.85, P<0.0001\right)$ and JRN $\left(F_{4}, 66=3.96, P=0.007\right)$. Microhabitat also influenced $T_{s}$ 's at $W S\left(F_{4,134}=4.10, P=0.004\right)$, but not at JRN $(P=0.10)$.

\section{DISCUSSION}

Variation in body temperature $\left(T_{b}\right)$ and thermoregulatory behavior within species are attributable to differences in the thermal environment via changing seasons, microhabitat selection, and altitude (Adolph 1990; Grant and Dunham 1990; Smith et al. 1993; Smith and Ballinger 1994; Van Damme et al. 1989, Van Damme et al. 1990). However, no studies have shown differences in these thermal relationships across populations at similar elevations and seasons. I found that two populations of Holbrookia maculata inhabiting 
thermally divergent environments, separated by only $60 \mathrm{~km}$ and at similar altitudes, showed differences in $\mathrm{T}_{\mathrm{b}}$ 's and thermoregulatory behavior.

Temperature regulation in lizards may be evaluated by examining the variance in $T_{b}$ 's of field-active individuals (Huey 1982). At WS, $\mathrm{T}_{b}$ 's were significantly lower than the $\mathrm{T}_{b}$ 's of lizards at JRN. This suggests that lizards at WS cannot regulate body temperatures as effectively as individuals at JRN. The environmental properties (biotic and abiotic) of the white gypsum dunes may hamper significant increases in Tb's. For example, $T_{s}$ 's at WS were lower than Tb's. Consequently, lizards at WS may be mostly restricted to direct heat uptake from solar radiation (heliothermically basking). In contrast, $\mathrm{T}_{s}$ 's at JRN were higher than $\mathrm{Tb}_{b}$ 's, suggesting that relatively more heat energy is stored in the substrate during the day at JRN than at WS. This would allow the JRN population to exploit another heat source in addition to solar radiation. A more complete picture of thermoregulation may be obtained by examining how Tb's vary with environmental temperatures.

A regression of $T_{b}$ on $T_{a}$ is another method of evaluating temperature regulation in lizards (Huey 1982). The slope from this linear relationship can indirectly identify the extent of thermoregulation. A slope near 0 suggests more precise regulation, whereas a slope near 1 suggests that body temperature depends upon ambient temperature. The slope calculated for $H$. maculata at WS is high (0.63) compared to the slope calculated for $H$. maculata at JRN (0.36), as well as compared to the slopes for other lizard species of the desert southwest. For example, reported slopes for Sceloporus jarrovi were 0.40 (Middendorf and Simon 1988) and 0.37 (Smith and Ballinger 1994). Smith et al. (1993) calculated a slope of 0.23 for Sceloporus scalaris and the slope for Urosaurus ornatus was 0.30 (Smith and Ballinger 1995). Sena (1978) reported a slope of 0.645 for $H$. maculata from eastern New Mexico. Interestingly, the slopes are similar for lizards at WS and at the quartz dunes of eastern New Mexico. Of those lizards studied, it appears that most species are relatively precise thermoregulators, whereas $H$. maculata shows interpopulational differences in control over thermoregulation.

Body temperature regulation via behavioral adjustments allows lizards to maintain fairly constant Tb's in an environment. Lizards of thermally heterogeneous environments have the potential to increase and maintain optimal $T_{b}$ 's that maximize performance, such as locomotion (Bennett 1980). However, when the thermal conditions are relatively homogeneous lizards could experience less that adequate thermal conditions (Huey and Bennett 1987) or remain inactive for extended periods of time (Grant and Dunham 1988, 1990). I found that microhabitat use, an index of behavioral thermoregulation, was different between lizards at WS and JRN, and that microhabitat influenced Tb's at WS, but not the Tb's at JRN. This suggests that the WS habitat is more thermally homogeneous than the environment at JRN. Moreover, the lizards at WS appear to thermoregulate in a limited sense by increasing $T_{b}$ 's throughout the morning and remaining active into the afternoon. In contrast, lizards at JRN appear to thermoregulate more carefully by obtaining activity $T_{b}$ 's at a relatively faster rate in the 
morning, then behaviorally regulate $\mathrm{T}_{\mathrm{b}}$ 's throughout the rest of the afternoon by shuttling between thermally appropriate microhabitats.

The morphology of $H$. maculata at WS may preclude significant increases in Tb's. First, lizards at WS are significantly lighter in dorsal coloration relative to those dorsal hues recorded from lizards at JRN (Hager 1998). Heat gain by a "white" lizard occurs at slower rates than the rate for darker individuals (Norris 1967; Porter et al. 1973). I observed lizards at WS to darken dorsally for only a short period of time in the early morning, but in a relative sense they do not darken to levels of lizards from areas outside WS (Hager 1998). Furthermore, heat gain and loss is influenced by the surface area to volume ratio of an animal (Porter et al. 1973; Stevenson 1985). Differences in body condition between each population suggest that lizards at WS have a lower surface area to volume ratio than lizards at JRN. Coloration and body size may reduce rates of heat gain in lizards at WS.

The data presented in this paper are preliminary, but they suggest that $T_{b}$ 's and thermoregulation vary between populations of $H$. maculata found in diverse thermal environments. At WS, it appears that relatively low air and soil temperatures, white body coloration, and a low estimate of body condition (a representation of the ratio between surface area and volume) may further influence $\mathrm{Tb}_{\mathrm{b}}$ 's. The precision, accuracy, and effectiveness of thermoregulation in $H$. maculata can be addressed by examining the relative distributions of lizard $T_{b}$ 's and operative temperatures of behaviorally-inert model lizards (Bakken 1992; Hertz et al. 1993). Furthermore, identifying the observed distributions of lizards into habitat categories relative to the actual distribution of the available habitat area into habitat categories is needed to more rigorously assess habitat selection (Grant and Dunham 1988).

\section{ACKNOWLEDGMENTS}

The administrators of White Sands National Monument provided all necessary permits and permission to work within the gypsum dunes. In particular, I thank Bill Fuchs and Bill Conrod, both of whom assisted me with the logistics of the research at White Sands. Carl Norris provided an enormous amount of computer assistance. Rich Spellenberg assisted with plant identification. I acknowledge Geoff Carpenter, George Middendorf, Craig Benkman, and Naida Zucker for their constructive criticisms of several aspects of my research. This research was funded, in part, by the Department of Biology, New Mexico State University.

\section{LITERATURE CITED}

ADOLPH, S. C.

1990. Influence of behavioral thermoregulation on microhabitat use by

two Sceloporus lizards. Ecology 71: 315-327. 
BAKKEN, G. S.

1992. Measurement and application of operative and standard operative temperatures in ecology. American Zoologist 32: 194-216.

BALLINGER, R. E. AND S. M. JONES.

1985. Ecological disturbance in a sandhills prairie: Impact and importance to the lizard community on Arapaho Prairie in western Nebraska. Prairie Naturalist 17: 91-100.

BASHEY, F. AND A. E. DUNHAM.

1997. Elevational variation in the thermal constraints on and microhabitat preferences of the greater earless lizard, Cophosaurus texanus. Copeia 1997: 725-737.

BENNETT, A. F.

1980. The thermal dependence of lizard behavior. Animal Behavior 28: 752-762.

BRATTSTROM, B. H.

1965. Body temperatures of reptiles. American Midland Naturalist 73: 376-422.

CLARKE, R. F.

1965. An ethological study of the Iguanid lizard

genera Callisaurus, Cophosaurus, and Holbrookia. Emporia State University Research Studies 13: 1-66.

COWLES, R. B. AND C. M. BOGERT.

1944. A preliminary study of the thermal requirements of desert reptiles. Bulletin of the American Museum of Natural History 83: 265-296.

DEGENHARDT, W. G., PAINTER, C. W. AND A. H. PRICE. 1996. Amphibians and reptiles of New Mexico. Univ. of New Mexico Press, Albuquerque, New Mexico.

DIXON, J. R. 1967. Aspects of the biology of the of lizards of the White Sands, New Mexico. Los Angeles County Museum, Contributions in Science 129: 1-22.

GRANT, B. W. AND A. E. DUNHAM. 1988. Thermally imposed time constraints on the activity of the desert lizard Sceloporus merriami. Ecology 69: 167-176. 1990. Elevational covariation in environmental constraints and life histories of the desert lizard Sceloporus merriami. Ecology 71: 1765-1776.

HAGER, S. B. 
1998. The thermoregulatory and reproductive behavior of the lesser earless lizard, Holbrookia maculata, at White Sands National Monument, New Mexico. PhD Dissertation, New Mexico State University.

HEATH, J. E.

1964. Reptilian thermoregulation: Evaluation of field studies. Science 145: 784785.

HERTZ, P. E., R. B. HUEY AND R. D. STEVENSON.

1993. Evaluating temperature regulation by field-active ectotherms: The fallacy of the inappropriate question. American Naturalist 142: 796-818.

HOUK, R. AND M. COLLIER.

1994. White Sands National Monument. Southwest Parks and Monuments Association, Tuscon, Arizona.

HUEY, R. B.

1982. Temperature, physiology, and the ecology of reptiles. Pages 25-91 in Biology of the Reptilia. Vol. 12, Physiology C: Physiological Ecology. (C. Gans and F. H. Pough eds). Academic Press, New York.

AND A. F. BENNETT.

1987. Phylogenetic studies of coadaptation: Preferred temperatures versus optimal performance temperatures of lizards. Evolution 41: 1098-1115.

E. R. PIANKA AND J. A. HOFFMAN.

1977. Seasonal variation in thermoregulatory behavior and body temperature of diurnal Kalahari lizards. Ecology 58: 1066-1075.

MIDDENDORF, G. A. AND C. A. SIMON.

1988. Thermoregulation in the iguanid lizard Sceloporus jarrovi: The influences of age, time, and light condition on body temperature and thermoregulatory behaviors. Southwestern Naturalist 33: 347-356.

NORRIS, K. S.

1967. Color adaptations in desert reptiles and its thermal relationships. Pages 163-229 in Lizard Ecology: A Symposium. (W. W. Milstead ed). University of Missouri Press, Columbia, Missouri.

PORTER, W. P., J. W. MITCHELL, W. A. BECKMAN AND C. B. DEWITT. 1973. Behavioral implications of mechanistic ecology. Thermal and behavioral modeling of desert ectotherms and their microenvironment. Oecologica (Berlin) 13: $1-54$.

RUTHVEN, A. G. 
1907. A collection of reptiles and amphibians from southern New Mexico and Arizona. Bulletin of the American Museum of Natural History 23: 483-604.

SAS INSTITUTE.

1995. Users Guide. Cary, North Carolina.

SENA, A. P.

1978. Temperature relations and the critical thermal maximum

of Holbrookia maculata maculata (Reptilia: Iguanidae). Southwestern Naturalist 23: 41-50.

SMITH, G. R. AND R. E. BALLINGER.

1994. Thermal ecology of Sceloporus virgatus from southeastern Arizona, with comparison to Urosaurus ornatus. Journal of Herpetology 28: 65-69.

1995. Temperature relationships of the tree lizard, Urosaurus ornatus, from desert and low-elevation montane populations in the southwestern USA. Journal of Herpetology 29: 126-129.

AND J. D. CONGDON.

1993. Thermal ecology of the high-altitude bunch grass lizard, Sceloporus scalaris. Canadian Journal of Zoology 71: 2152-2155.

STEVENSON, R. D.

1985. Body size and limits to the daily range of body temperature in terrestrial ectotherms. American Naturalist 125: 102-117.

VAN DAMME, R., D. BAUWENS, A. M. CASTILLA AND R. F. VERHEYEN. 1989. Altitudinal variation of the thermal biology and running performance in the lizard Podacris tiliguerta. Oecologia (Berlin) 80: 516-524.

AND R. F. VERHEYEN.

1990. Evolutionary rigidity of thermal physiology: the case of the cool temperate lizard Lacerta vivipara. Oikos 57: 61-67.

WEAST, R. C., ed.

1986. CRC Handbook of Chemistry and Physics. CRC Press, New York.

WHEELER, R. J., S. R. LECROY, C. H. WHITLOCK, G. C. PURGOLD AND J. S. SWANSON.

1994. Surface characteristics for the alkali flats and dunes regions at White Sands Missile Range, New Mexico. Remote Sensing and Environment 48: 181 190.

ZAR, J. H. 
1984. Biostatistical Analysis. Second Edition. Prentice Hall, Englewood Cliffs, New Jersey.

Submitted: Friday 26 March 1999 